\title{
Progress and Regress of Time Dependent Data and Application in Bank Branch
}

\author{
F. Hosseinzadeh Lotfi, Z. Taeb, and S. Abbasbandy \\ Department of Mathematics, Islamic Azad University, Science \& Research Branch, Iran \\ Correspondence should be addressed to Z. Taeb; taeb_zt@yahoo.com
}

Received 23 January 2014; Accepted 1 February 2014; Published 23 April 2014

Academic Editor: Mohammad Khodabakhshi

Copyright (C) 2014 F. Hosseinzadeh Lotfi et al. This is an open access article distributed under the Creative Commons Attribution License, which permits unrestricted use, distribution, and reproduction in any medium, provided the original work is properly cited.

To evaluate each decision making unit having time dependent inputs and outputs data, a new method has been developed and reported here. This method uses the Malmquist productivity index, and is a very simple function based on Cubic Spline function to determine the progress and regress of that unit. To show the capability of this developed method, the data of 9 branches of a commercial bank has been used, evaluated, and reported.

\section{Introduction}

In the modern managements, several applied scientific methods have been developed to improve the quality of systems. Data Envelopment Analysis (DEA) is one of the most suitable and applicable methods to evaluate and compare several units or a unit in various times [1-3]. By using this scientific technique, the system manager is in the position to find and apply the best decision for improving that system $[4,5]$.

At the beginning, the efficiency change was the only possible criteria to find the progress and regress of a unit. Via research developments, it has been shown that the technical change has effect in productivity, too, and the Malmquist Productivity Index (MPI) was introduced by Malmquist in 1953 [6]. Later the researchers recommended productivity evaluation and defined MPI for each unit based on inputs disposal and outputs products [7-10]. Hereafter several researches focused on calculating this index and several applications were procured [11-13].

Those evaluations used fixed and certain values of the units and excluded some application cases, which have used the time dependent available or foresight data [14-16]. To determine the progress and regress of a Decision Making Unit (DMU) is necessary to use models with time dependent data analysis capability.

In this paper, the definition of MPI will be illustrated [1719], then the efficiency of time dependent data will be defined, and a new method to determine progress and regress of units will be presented and applied for a commercial bank and the results will be discussed.

\section{Malmquist Productivity Index}

Farell (1957) determined a suitable method to evaluate experimental production function for several inputs and outputs with using linear programming technique and Data Envelopment Analyses (DEA) [20]. By applying DEA, the best efficiency frontier will be calculated with a set of DMUs and omitting of any priority for inputs and outputs. The DMUs of efficiency frontier are the units with the maximum output and/or the minimum input levels. Using the efficient units and efficiency frontier, the analysis of other inefficiency units is possible.

MPI is defined with assimilation efficiency changes of each unit and technology changes. MPI can be calculated via several functions, such as distance function

$$
D\left(X_{\circ}, Y_{\circ}\right)=\inf \left\{\frac{\theta}{\left(\theta X_{\circ}, Y_{\circ}\right)} \in \operatorname{PPS}\right\} .
$$

This equation shows in special conditions only the efficiency frontier change at time $t+1$ related to $t$ that could not be a suitable criterion to calculate the technology change. If $D^{k}\left(X^{k}, Y^{k}\right)=1$, then $k$ th unit is hypothesized as efficient. 
This distance function does not define the inefficiency values. Fare decomposed MPI into two components, using linear inefficiency of technology frontier. The efficiency frontier will be specified for each DMU with DEA. Production function is hypothesized instant $t$ and $t+1$. Calculation of the MPI requires four linear programming problems as follows:

$$
\begin{gathered}
\circ \in Q=\{1,2, \ldots, n\}, \\
D_{\circ}^{t}\left(X_{\circ}^{t}, Y_{\circ}^{t}\right)=\operatorname{Min} \theta, \\
\text { s.t. } \quad \sum_{j=1}^{n} \lambda_{j} x_{i j}^{t} \leq \theta x_{i o}^{t}, \quad i=1, \ldots, m, \\
\sum_{j=1}^{n} \lambda_{j} y_{r j}^{t} \geq y_{r o}^{t}, \quad r=1, \ldots, s, \\
\lambda_{j} \geq 0, \quad j=1, \ldots, n .
\end{gathered}
$$

$x_{i o}^{t}$ is the $i$ th input and $y_{r o}^{t}$ is the $r$ th output of DMU。 at time $t$. The efficiency $\left(D_{\circ}^{t}\left(X_{\circ}^{t}, Y_{\circ}^{t}\right)=\theta_{\circ}^{*}\right)$ shoes the highest possible decrease of DMU。 input for related output.

Instead $t$, CCR problem (2), is calculated at time $t+1$ and is equal to $D^{t+1}\left(X_{\circ}^{t+1}, Y_{\circ}^{t+1}\right)$ and is the technical efficiency for $\mathrm{DMU}_{\text {。 }}$ at time $t+1$. The value of $D^{t}\left(X_{\circ}^{t+1}, Y_{\circ}^{t+1}\right)$ for DMU。 is the distance of $\mathrm{DMU}_{0}$ at $t+1$ with the frontier of time $t$, calculated by the following problem:

$$
\begin{gathered}
D^{t}\left(X_{\circ}^{t+1}, Y_{\circ}^{t+1}\right)=\operatorname{Min} \theta, \\
\text { s.t. } \quad \sum_{j=1}^{n} \lambda_{j} x_{i j}^{t} \leq \theta x_{i o}^{t+1}, \quad i=1, \ldots, m, \\
\sum_{j=1}^{n} \lambda_{j} y_{r j}^{t} \geq y_{r o}^{t+1}, \quad r=1, \ldots, s, \\
\lambda_{j} \geq 0, \quad j=1, \ldots, n .
\end{gathered}
$$

The same model $D^{t+1}\left(X_{\circ}^{t}, Y_{\circ}^{t}\right)$ is calculated:

$$
\begin{gathered}
D^{t+1}\left(X_{\circ}^{t}, Y_{\circ}^{t}\right)=\operatorname{Min} \theta, \\
\text { s.t. } \quad \sum_{j=1}^{n} \lambda_{j} x_{i j}^{t+1} \leq \theta x_{i o}^{t}, \quad i=1, \ldots, m, \\
\sum_{j=1}^{n} \lambda_{j} y_{r j}^{t+1} \geq y_{r o}^{t}, \quad r=1, \ldots, s, \\
\lambda_{j} \geq 0, \quad j=1, \ldots, n .
\end{gathered}
$$

Fare hypotheses $D_{\circ}^{t+1}\left(X_{\circ}^{t+1}, Y_{\circ}^{t+1}\right), D_{\circ}^{t}\left(X_{\circ}^{t}, Y_{\circ}^{t}\right)$ must be equal to 1 to be efficient. Therefore he defined relative efficiency change as

$$
\mathrm{TEC}_{\circ}=\frac{D_{\circ}^{t+1}\left(X_{\circ}^{t+1}, Y_{\circ}^{t+1}\right)}{D_{\circ}^{t}\left(X_{\circ}^{t}, Y_{\circ}^{t}\right)}
$$

He described one geometric compotation to determine technology change between $t$ and $t+1$ :

$$
\mathrm{FS}_{\circ}=\left[\frac{D_{\circ}^{t}\left(X_{\circ}^{t+1}, Y_{\circ}^{t+1}\right)}{D_{\circ}^{t+1}\left(X_{\circ}^{t+1}, Y_{\circ}^{t+1}\right)} \cdot \frac{D_{\circ}^{t}\left(X_{\circ}^{t}, Y_{\circ}^{t}\right)}{D_{\circ}^{t+1}\left(X_{\circ}^{t}, Y_{\circ}^{t}\right)}\right]^{1 / 2}
$$

MPI will be calculated from multiplication efficiency change and technology change for each input oriented DMU at time $t$ and $t+1$ :

$$
\begin{aligned}
M_{\circ}= & \frac{D_{\circ}^{t+1}\left(X_{\circ}^{t+1}, Y_{\circ}^{t+1}\right)}{D_{\circ}^{t}\left(X_{\circ}^{t}, Y_{\circ}^{t}\right)} \\
& \times\left[\frac{D_{\circ}^{t}\left(X_{\circ}^{t+1}, Y_{\circ}^{t+1}\right)}{D_{\circ}^{t+1}\left(X_{\circ}^{t+1}, Y_{\circ}^{t+1}\right)} \cdot \frac{D_{\circ}^{t}\left(X_{\circ}^{t}, Y_{\circ}^{t}\right)}{D_{\circ}^{t+1}\left(X_{\circ}^{t}, Y_{\circ}^{t}\right)}\right]^{1 / 2} .
\end{aligned}
$$

The simple form of relation (9) is

$$
M_{\circ}=\left[\frac{D_{\circ}^{t}\left(X_{\circ}^{t+1}, Y_{\circ}^{t+1}\right)}{D_{\circ}^{t}\left(X_{\circ}^{t}, Y_{\circ}^{t}\right)} \cdot \frac{D_{\circ}^{t+1}\left(X_{\circ}^{t+1}, Y_{\circ}^{t+1}\right)}{D_{\circ}^{t+1}\left(X_{\circ}^{t}, Y_{\circ}^{t}\right)}\right]^{1 / 2} .
$$

This value defines geometric convex compotation, because it specified the smallest decrease of efficiencies and any small change in each efficiency effect in MPI. Three conditions are available.

(1) $M_{\circ}>1$; increase productivity and observe progress.

(2) $M_{\circ}<1$; decrease productivity and observe regress.

(3) $M_{\circ}=1$; no change is seen in productivity at time $t+1$ in comparison to $t$.

\section{Efficiency of Time Dependent Units}

Usually, study cases have time dependent inputs and outputs, and their efficiency is managers' interest. In this relation a time dependent function is necessary to evaluate the efficiency of this kind of data in virtual intervals.

A system that includes $n$ DMUs which include $m$ inputs and $s$ outputs is supposed. Inputs and outputs may be a function dependent on time; then assume that $f_{i p}(t)$ and $g_{o p}(t)$ are $i$ th inputs and oth output of $\mathrm{DMU}_{p}$. As this, each DMU is represented as

$\mathrm{DMU}_{p}$

$$
=\left(f_{1 p}(t), f_{2 p}(t), \ldots, f_{m p}(t), g_{1 p}(t), g_{2 p}(t), \ldots, g_{s p}(t)\right)^{t}
$$

These functions can contemplate linear or nonlinear and may be constant. To calculate the efficiency of $\mathrm{DMU}_{p}$, in case of known function, for some $t$ the inputs and outputs will be in hand. In some interval $[a, b]$, this parameter may assume random numbers. By using uniform distribution it may be supposed that

$$
t_{i}=a+(b-a) d_{i}, \quad i=1, \ldots, r,
$$

where $r$ is the number of numeral used in this interval and $d_{i}$ are random numbers (without losing the generality, we 
assume that $t_{i}$ are distinct). At first, the time points $t_{i}$ will be sorted in an increasing order and then named $w_{i}$ and indeed $a=w_{0}$ and $b=w_{r+1}$. Because of this, in the fixed amount of $r$, all inputs and outputs for any DMUs are fixed also. For each $t$, all DMUs are fixed. Because of this, in the fixed amount of $r$, all inputs and outputs for any DMUs are fixed, also. For each $t$, all DMUs are fixed; and the efficiency of $\mathrm{DMU}_{p}$ will be determined by using CCR model. To find the efficiency, it is necessary to solve $n$ linear programs (LPs). Therefore, always the number of LPs is more. In supposed model, only distinguished number models are solved and, by estimating the function of efficiency, efficiency of ideal $t$ is known.

The efficiency of time dependent data will be as follows according to the Cubic Spline function for $p$ th DMU:

$$
\theta(t)=\operatorname{Min}\left\{\theta_{i}(t), 1\right\} \quad \text { for } t \in\left[w_{i-1}, w_{i}\right], i=1, \ldots, r+1 \text {. }
$$

That $\theta_{i}(t)$ is determined by

$$
\begin{aligned}
\theta_{i}(t)= & \alpha_{i}+\beta_{i}\left(t-w_{i-1}\right)+\gamma_{i}\left(t-w_{i-1}\right)^{2} \\
& +\delta_{i}\left(t-w_{i-1}\right)^{3}, \quad i=1, \ldots, r+1 .
\end{aligned}
$$

By calculating the efficiency values in some times $(k)$ of this interval Cubic Spline function can be predicted. This data is very close to efficiency function and has less calculating error.

The goal of this study was to determine the progress and regress of time dependent DMUs. Following a simple method will be illustrated in this relation.

\section{The Progress and Regress of Time Dependent Units}

Here the value of progress and regress of time dependent data will be introduced and the developed method will be schemed and reported.

4.1. Assumed. As the inputs and outputs of each DMU are functions dependent on time, the centers of gravity of each subinterval are estimated.

In supposed method, at first the interval $[a, b]$ will be divided into $n$ subintervals, showed by $I_{k}=\left[a_{k}, b_{k}\right]$. Here we hypothesize that the DMUs have $m$ inputs and $s$ outputs that are functions of time. Then $\mathrm{DMU}_{j}=\left(X_{j}, Y_{j}\right), j=1, \ldots, n$ are defined as follow:

$$
\begin{aligned}
X_{j} & =\left(f_{1 j}(t), f_{2 j}(t), \ldots, f_{m j}(t)\right), \\
Y_{j} & =\left(g_{1 j}(t), g_{2 j}(t), \ldots, g_{s j}(t)\right) .
\end{aligned}
$$

In each subinterval $I_{k}$, an indicator can be set. To compute the mention coordinates, the centers of gravity of inputs and outputs are determined. These are contemplating as follows.

$P_{i k}^{j}$ : the center of gravity of $\mathrm{DMU}_{j}$ for $i$ th input in $I_{k}$.

$$
Q_{r k}^{j} \text { : the center of gravity of } \mathrm{DMU}_{j} \text { for } r \text { th output in } I_{k} \text {. }
$$

The center of gravity coordinate is showed as

$$
P_{i k}^{j}=\left(\bar{t}_{i k}, \bar{x}_{i k}\right), \quad Q_{r k}^{j}=\left(\bar{t}_{r k}, \bar{y}_{r k}\right),
$$

$\bar{t}_{i k}$ and $\bar{x}_{i k}$ are calculated by

$$
\begin{array}{r}
\bar{t}_{i k}^{j}=\frac{\int_{a_{k}}^{b_{k}} t \cdot f_{i j}(t) d t}{\int_{a_{k}}^{b_{k}} f_{i j}(t) d t} \quad \bar{x}_{i k}^{j}=\frac{(1 / 2) \int_{a_{k}}^{b_{k}}\left(f_{i j}(t)\right)^{2} d t}{\int_{a_{k}}^{b_{k}} f_{i j}(t) d t}, \\
i=1, \ldots, m .
\end{array}
$$

And the $\bar{t}_{r k}$ and $\bar{y}_{r k}$ are computed:

$$
\bar{t}_{r k}^{j}=\frac{\int_{a_{k}}^{b_{k}} t \cdot g_{r j}(t) d t}{\int_{a_{k}}^{b_{k}} g_{r j}(t) d t}, \quad \bar{y}_{r k}^{j}=\frac{(1 / 2) \int_{a_{k}}^{b_{k}}\left(g_{r j}(t)\right)^{2} d t}{\int_{a_{k}}^{b_{k}} g_{r j}(t) d t},
$$

Because of the above formula, the indicators of each subinterval are determined by

$$
\begin{array}{r}
m_{k}^{j}=\left(P_{i k}^{j}, Q_{r k}^{j}\right), \quad i=1, \ldots, m, r=1, \ldots, s, \\
k=1, \ldots, n-1 .
\end{array}
$$

These indicators are distinct; then the MPI should be exploited by using (8).

4.2. The Malmquist Productivity Index for Time Dependent Data. At first the centers of gravity of each subinterval are taken into consideration. As the functions are dependent on one variable, the first quantities are not used to calculate. Therefore the center of gravity is

$$
P_{i k}^{j}=\left(\bar{x}_{i k}\right), \quad Q_{r k}^{j}=\left(\bar{x}_{r k}\right), \quad i=1, \ldots, m, r=1, \ldots, s,
$$

If $m$ inputs and $s$ outputs are available, then $n s+n m$ notes should be computed; they are remembered by (17).

The MPI index for $m_{1}^{j}, \ldots, m_{k}^{j}$ is considered by $M_{k}^{j}$ in subinterval $I_{k}$. All subintervals may be compared with each other. These values show the scope of progress and regress between two consecutive subintervals. If the calculative value is more than 1 , this unit has progress, and for less than one the unit demonstrates regress. Otherwise it does not show any changes.

The managers understand DMU behavior in subintervals by using this comparison and have the possibility to apply this data for scientific evaluations.

The goal of this study is to define and set a time dependent function of progress and regress in $[a, b]$. By applying this function, man can estimate the unit change in the particular important time.

In Section 2, the Cubic Spline function was offered as a suitable approximation. The one variable function $M_{j}(t)$ is 


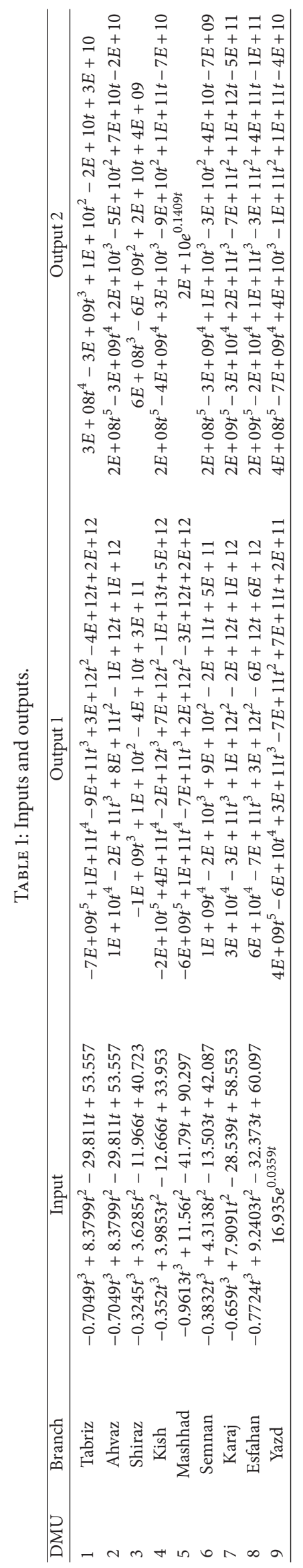


TABLE 2: The input and outputs center of gravity for $\mathrm{DMU}_{1}$.

\begin{tabular}{lccccc}
\hline Month & First & Second & Third & Fourth & 12.7758 \\
$X(t)$ & 13.0252 & 10.3282 & 10.8812 & 12.3981 & $1.22 E+13$ \\
$Y_{1}(t)$ & $8.63 E+10$ & $3.59 E+11$ & $1.62 E+12$ & $5.14 E+12$ & $3.73 E+09$ \\
$Y_{2}(t)$ & $7.09 E+09$ & $3.95 E+09$ & $3.46 E+09$ & $1.68 E+10$ \\
\hline
\end{tabular}

TABLE 3: The input and outputs center of gravity for $\mathrm{DMU}_{2}$.

\begin{tabular}{lccccc}
\hline Month & First & Second & Third & Fourth & Fifth \\
\hline$X(t)$ & 13.0252 & 10.3282 & 10.8812 & 12.3981 & 12.7758 \\
$Y_{1}(t)$ & $3.41 E+11$ & $3.71 E+11$ & $3.48 E+11$ & $8.91 E+11$ & $2.37 E+12$ \\
$Y_{2}(t)$ & $1.41 E+10$ & $3.10 E+10$ & $6.62 E+10$ & $1.27 E+11$ & $2.30 E+11$ \\
\hline
\end{tabular}

supposed for the evaluation of MPI of $\mathrm{DMU}_{j}$. To determine this function, the values $M_{k}^{j}$ calculated by center of gravity are used. These are the evaluation between $\left(P_{i l}^{j}, Q_{r l}^{j}\right)$ and $\left(P_{i l+1}^{j}, Q_{r l+1}^{j}\right)$ for $l=1, \ldots, n$. Therefore $n-2$ values of MPI are in hand. By using these values, the Malmquist function can be calculated. This function should be a piecewise linear function. This function should be a piecewise linear function. It will be computed in interval $I_{k}$ by Cubic Spline function as

$$
\begin{array}{r}
M_{k}^{j}(t)=\alpha_{j}+\beta_{j}\left(t-M_{k}^{j}\right)+\gamma_{j}\left(t-M_{k}^{j}\right)^{2}+\delta_{j}\left(t-M_{k}^{j}\right)^{3}, \\
k=1, \ldots, n, \quad j=1, \ldots, n .
\end{array}
$$

In the vole of hypotheses interval the MPI is computed with (20) for $\mathrm{DMU}_{j}$ :

$$
M_{\mathrm{DMU}_{j}}(t)=\left\{\begin{aligned}
M_{1}^{j}(t) ; & t \in\left[a_{1}, b_{1}\right] \\
M_{2}^{j}(t) ; & t \in\left[a_{2}, b_{2}\right] \\
\cdot & \\
\cdot & \\
\cdot & \\
M_{n}^{j}(t) ; & t \in\left[a_{n}, b_{n}\right] .
\end{aligned}\right.
$$

Function 20 determines the value of MPI at the defined special time. The following cases are possible.

(A) If the function value is more than one during consideration time, the DMU has progress.

(B) If the function value is less than one during consideration time, the DMU has regress.

(C) Otherwise, the intersection of this function and line one is necessary to calculate. The sums of function integral of regions above and under mentioned line 1 should be subtracted. If this difference is more than zero the DMU has progress, and if it is less than zero, the evaluated DMU has regress.
To explain case $(\mathrm{C})$, suppose the above region functions are $M_{l}(t), M_{m}(t)$, and $M_{n}(t)$ and the below functions are $M_{r}(t)$, $M_{s}(t), M_{t}(t)$, and $M_{u}(t)$; then,

$$
\begin{gathered}
S_{1}=\int_{a_{1}}^{b_{1}} M_{l}(t) d t+\int_{a_{2}}^{b_{2}} M_{m}(t) d t+\int_{a_{3}}^{b_{3}} M_{n}(t) d t, \\
S_{2}=\int_{a_{4}}^{b_{4}} M_{r}(t) d t+\int_{a_{5}}^{b_{5}} M_{s}(t) d t \\
+\int_{a_{6}}^{b_{6}} M_{t}(t) d t+\int_{a_{7}}^{b_{7}} M_{u}(t) d t .
\end{gathered}
$$

And $\left[a_{i}, b_{i}\right]$ are the intersections point; according to this,

$$
S=S_{1}-S_{2}
$$

is the criterion of progress and regress.

(1) If $S<0$ then the DMU has progress in the evaluated interval.

(2) If $S>0$ then the DMU has regress in the evaluated interval.

(3) Otherwise the DMU does not have any changes in this evaluation interval.

The proposed method of this study should be assigned with simple calculation and solving $n-2$ linear programing. Therefore this method is very useful and when the Malmquist function is set, for each time, the system programmer can determine the progress and regress with replacing the considered time of this function.

\section{Application}

In this section, the application of the mentioned method will be reported for studying the progress and regress of nine commercial bank branches in Iran.

These branches have similar time dependent data. The input is the personal value and the relevant outputs are the sum of four deposits and interest, which are linear or nonlinear function of time. The units are as in Table 1.

The study interval was $[1,6]$. By using (18), the center of the gravity for DMUs is calculated. Each month is supposed to be a subinterval. These centers are shown in Tables 2, 3, 4, $5,6,7,8,9$ and 10 . 
TABLE 4: The input and outputs center of gravity for $\mathrm{DMU}_{3}$.

\begin{tabular}{lccccc}
\hline Month & First & Second & Third & Fourth & Fifth \\
\hline$X(t)$ & 15.0275 & 14.2578 & 14.7013 & 15.3614 & 15.2734 \\
$Y_{1}(t)$ & $1.30 E+11$ & $1.24 E+11$ & $1.20 E+11$ & $1.16 E+11$ & $1.08 E+11$ \\
$Y_{2}(t)$ & $1.12 E+10$ & $1.29 E+10$ & $1.31 E+10$ & $1.37 E+10$ & $1.64 E+10$ \\
\hline
\end{tabular}

TABLE 5: The input and outputs center of gravity for $\mathrm{DMU}_{4}$.

\begin{tabular}{lccccc}
\hline Month & First & Second & Third & Fourth & Fifth \\
\hline$X(t)$ & 11.4851 & 14.2578 & 11.696 & 12.7644 & 13.0662 \\
$Y_{1}(t)$ & $7.86 E+11$ & $3.74 E+12$ & $1.08 E+13$ & $2.49 E+13$ & $4.93 E+13$ \\
$Y_{2}(t)$ & $2.03 E+10$ & $2.46 E+10$ & $1.69 E+10$ & $1.87 E+10$ & $5.12 E+10$ \\
\hline
\end{tabular}

TABLE 6: Input and outputs center of gravity for $\mathrm{DMU}_{5}$.

\begin{tabular}{lccccc}
\hline Month & First & Second & Third & Fourth & Fifth \\
\hline$X(t)$ & 25.6474 & 21.7128 & 22.2869 & 24.3196 & 24.928 \\
$Y_{1}(t)$ & $1.83 E+11$ & $3.99 E+11$ & $1.19 E+12$ & $2.56 E+12$ & $4.77 E+12$ \\
$Y_{2}(t)$ & $8.71 E+08$ & $1.00 E+09$ & $1.15 E+09$ & $1.33 E+09$ & $1.53 E+09$ \\
\hline
\end{tabular}

TABLE 7: The input and outputs center of gravity for $\mathrm{DMU}_{6}$.

\begin{tabular}{lccccc}
\hline Month & First & Second & Third & Fourth & 17.1966 \\
$X(t)$ & 15.2452 & 14.7128 & 15.6412 & 16.8485 & $4.69 E+11$ \\
$Y_{1}(t)$ & $1.71 E+11$ & $1.44 E+11$ & $9.96 E+10$ & $2.05 E+11$ & $1.66 E+11$ \\
$Y_{2}(t)$ & $5.80 E+09$ & $2.51 E+10$ & $8.55 E+10$ & $3.99 E+11$ \\
\hline
\end{tabular}

TABLE 8: The input and outputs center of gravity for $\mathrm{DMU}_{7}$.

\begin{tabular}{lccccc}
\hline Month & First & Second & Third & Fourth & Fifth \\
\hline$X(t)$ & 15.9811 & 13.2981 & 13.7001 & 15.0854 & 15.4789 \\
$Y_{1}(t)$ & $3.31 E+11$ & $6.56 E+11$ & $1.07 E+12$ & $1.37 E+12$ & $1.11 E+12$ \\
$Y_{2}(t)$ & $3.30 E+10$ & $1.24 E+11$ & $2.27 E+11$ & $2.73 E+11$ & $1.99 E+11$ \\
\hline
\end{tabular}

Between each two subintervals, the MPI is rated by using formula (8). These values are reported in Table 11.

Because of 6-month study duration, four indexes are reported for each branch and the Cubic Spline functions of these amounts are introduced as follow:

$$
\begin{gathered}
M_{1}(t)=0.5837 t^{3}-7.3715 t^{2}+29.3121-t 33.0331 \\
M_{2}(t)=0.2368 t^{3}-2.6753 t^{2}+1.2343 t-9.0667 \\
M_{3}(t)=-0.0108 t^{3}+0.2168 t^{2}-9.6318 t-3.1143, \\
M_{4}(t)=0.3868 t^{3}-4.6083 t^{2}+16.7943 t-15.3944 \\
M_{5}(t)=0.3408 t^{3}-4.2112 t^{2}+16.3108 t-17.2072, \\
M_{6}(t)=0.3202 t^{3}-3.9928 t^{2}+15.516 t-15.9178, \\
M_{7}(t)=-0.2917 t^{3}+4.089 t^{2}-31.8263 t+19.3241,
\end{gathered}
$$

$$
\begin{gathered}
M_{8}(t)=-2.1667 t^{3}+26.333 t^{2}-101.153 t+124.5783 \\
M_{9}(t)=0.9095 t^{3}-11.0407 t^{2}+43.0116 t-51.6083
\end{gathered}
$$

With drawing these functions plotted in Figures 1, 2, 3, 4, 5, 6, 7,8 , and 9 , researchers can consider and analyze the functions easily.

As shown in Figures 1 to $9, \mathrm{DMU}_{1}$ and $\mathrm{DMU}_{2}$ have progress because their relative diagram values are more than one for all points in supposed interval; the diagram value of $\mathrm{DMU}_{2}$ is higher than $\mathrm{DMU}_{1}$; it demonstrates that this unit has more progress than the other.

The $\mathrm{DMU}_{1}, \mathrm{DMU}_{4}, \mathrm{DMU}_{5}$, and $\mathrm{DMU}_{6}$ have progress with decreasing in their values. $\mathrm{DMU}_{2}$ fluctuates at first but increases gradually. $\mathrm{DMU}_{9}$ changes in interval $[1,6]$. DMU 6 progress is higher than $\mathrm{DMU}_{5}$ and less than $\mathrm{DMU}_{1}$ and $\mathrm{DMU}_{4}$. 
TABLE 9: The input and outputs center of gravity for $\mathrm{DMU}_{8}$.

\begin{tabular}{lccccc}
\hline Month & First & Second & Third & Fourth & Fifth \\
\hline$X(t)$ & 15.2414 & 12.5698 & 13.5039 & 15.5444 & 16.3844 \\
$Y_{1}(t)$ & $8.96 E+11$ & $5.84 E+11$ & $3.83 E+11$ & $3.32 E+11$ & $1.41 E+12$ \\
$Y_{2}(t)$ & $3.71 E+10$ & $1.03 E+11$ & $2.02 E+10$ & $1.92 E+11$ & $8.76 E+11$ \\
\hline
\end{tabular}

TABLE 10: Input and outputs center of gravity for $\mathrm{DMU}_{9}$.

\begin{tabular}{lccccc}
\hline Month & First & Second & Third & Fourth & Fifth \\
\hline$X(t)$ & 0.1604 & 0.1663 & 0.1723 & 0.1786 & 0.1852 \\
$Y_{1}(t)$ & $2.06 E+11$ & $1.55 E+11$ & $6.64 E+11$ & $4.29 E+11$ & $1.03 E+12$ \\
$Y_{2}(t)$ & $6.86 E+09$ & $1.24 E+10$ & $2.22 E+10$ & $5.72 E+10$ & $1.34 E+11$ \\
\hline
\end{tabular}

TABLE 11: The Malmquist productivity index.

\begin{tabular}{lcccc}
\hline DMU & $M_{1}$ & $M_{2}$ & $M_{3}$ & $M_{4}$ \\
\hline $\mathrm{DMU}_{1}$ & 3.295 & 4.283 & 2.785 & 2.303 \\
$\mathrm{DMU}_{2}$ & 1.993 & 2.027 & 1.684 & 2.385 \\
$\mathrm{DMU}_{3}$ & 1.214 & 0.985 & 0.962 & 1.08 \\
$\mathrm{DMU}_{4}$ & 3.834 & 3.52 & 2.113 & 1.934 \\
$\mathrm{DMU}_{5}$ & 2.575 & 2.906 & 1.972 & 1.818 \\
$\mathrm{DMU}_{6}$ & 2.92 & 3.204 & 2.226 & 1.907 \\
$\mathrm{DMU}_{7}$ & 4.515 & 1.777 & 1.092 & 0.71 \\
$\mathrm{DMU}_{8}$ & 2.422 & 0.225 & 5.194 & 4.329 \\
$\mathrm{DMU}_{9}$ & 1.127 & 2.678 & 1.247 & 2.291 \\
\hline
\end{tabular}

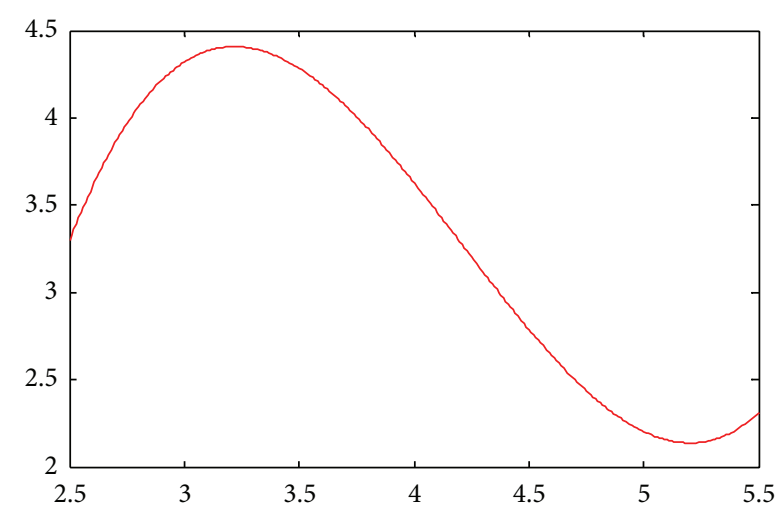

FIgURE 1: The diagram of Malmquist product index $\mathrm{DMU}_{1}$.

Because $\mathrm{DMU}_{3}, \mathrm{DMU}_{7}$, and $\mathrm{DMU}_{8}$ cut the line 1 , so it is necessary to calculate the intersection points and related regions.

$\mathrm{DMU}_{3}$ cuts the line at two points in the mentioned interval. The amount of function will be set zero, when the function value is less than zero. The values of the areas are

$$
\begin{aligned}
S_{1}= & \int_{2.5}^{3.3956}\left(-0.0108 t^{3}+0.2168 t^{2}-9.6318 t-3.1143\right) d t \\
& +\int_{4.8912}^{5.5}\left(-0.0108 t^{3}+0.2168 t^{2}-9.6318 t-3.1143\right) d t \\
= & 1.6107,
\end{aligned}
$$

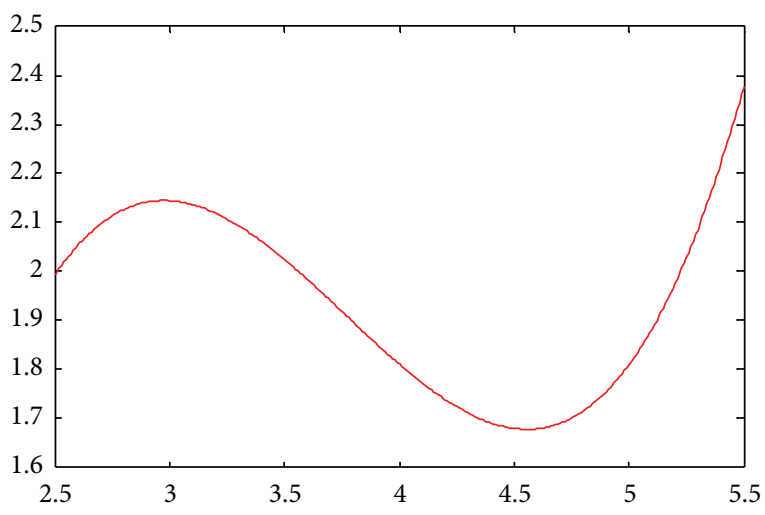

FIGURE 2: The diagram of Malmquist product index $\mathrm{DMU}_{2}$.

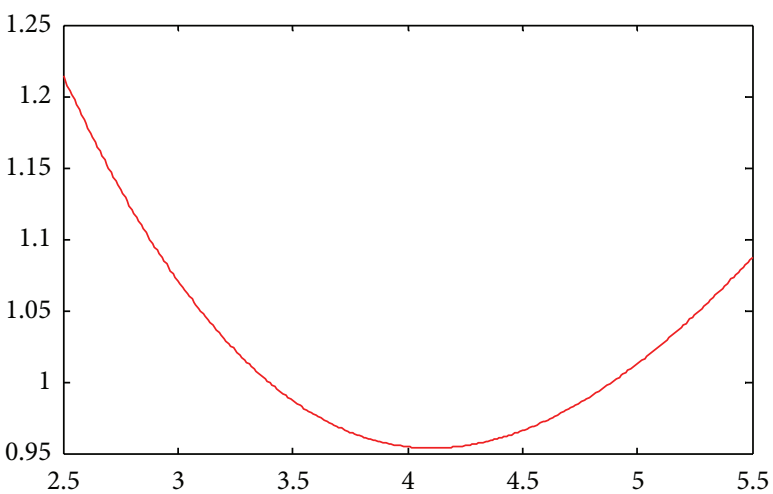

FIGURE 3: The diagram of Malmquist product index $\mathrm{DMU}_{3}$.

$$
\begin{aligned}
S_{2} & =\int_{3.3956}^{4.8912}\left(-0.0108 t^{3}+0.2168 t^{2}-9.6318 t-3.1143\right) d t \\
& =1.4496 .
\end{aligned}
$$

This unit has progress in the interval. It observes decreasing and, after point 4.8912, increases. This is to see in Table 11, too. $\mathrm{DMU}_{7}$ also cuts the line in one point. These spaces are 


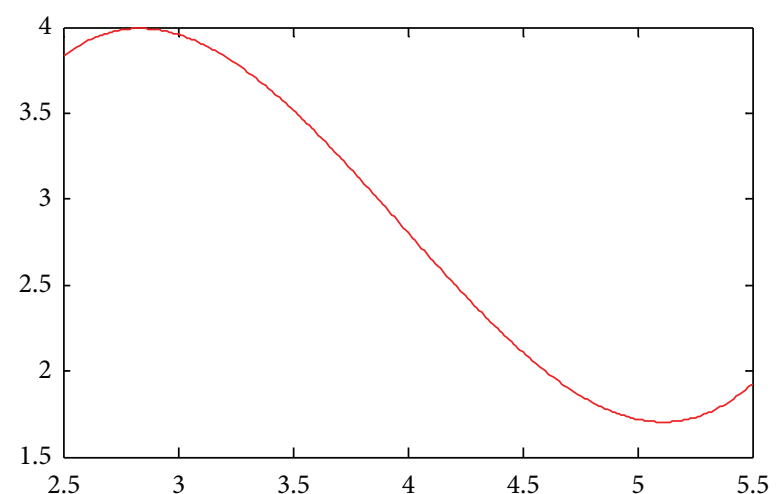

FIgURE 4: The diagram of Malmquist product index $\mathrm{DMU}_{4}$.

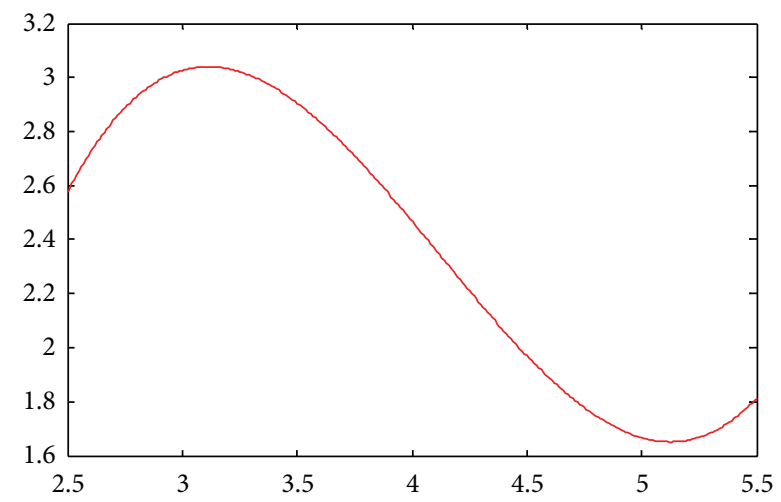

FIgURE 5: The diagram of Malmquist product index $\mathrm{DMU}_{5}$.

determined as (25), so this units has progress, too. Consider the following:

$$
\begin{aligned}
S_{1} & =\int_{2.5}^{4.8881}\left(-0.2917 t^{3}+4.089 t^{2}-31.8263 t+19.3241\right) d t \\
& =4.6408 \\
S_{2} & =\int_{4.8881}^{5.5}\left(-0.2917 t^{3}+4.089 t^{2}-31.8263 t+19.3241\right) d t \\
& =0.5383 .
\end{aligned}
$$

For the range of less than zero value of the efficiency function value related to $\mathrm{DMU}_{8}$, those values will be set equal zero. Consider the following:

$S_{1}$

$$
\begin{aligned}
= & \int_{2.5}^{2.6675}\left(-2.1667 t^{3}+26.333 t^{2}-101.153 t+124.5783\right) d t \\
& +\int_{3.6872}^{5.5}\left(-2.1667 t^{3}+26.333 t^{2}-101.153 t+124.5783\right) d t \\
= & 8.6052,
\end{aligned}
$$

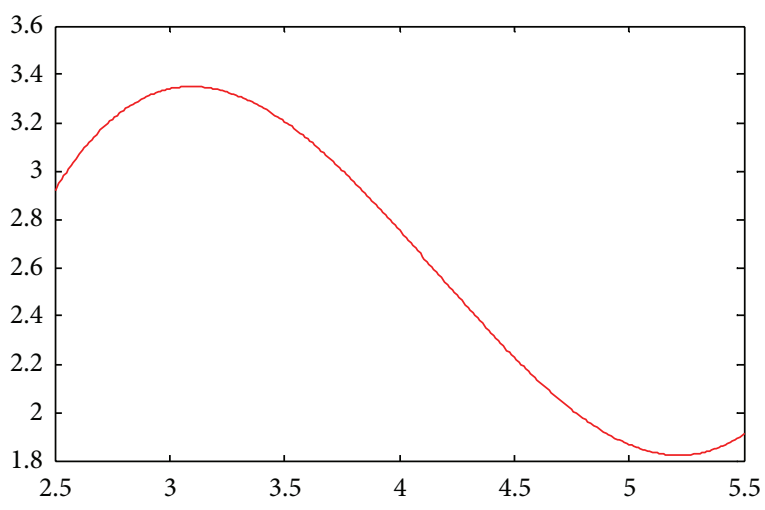

FIgUre 6: The diagram of Malmquist product index $\mathrm{DMU}_{6}$.

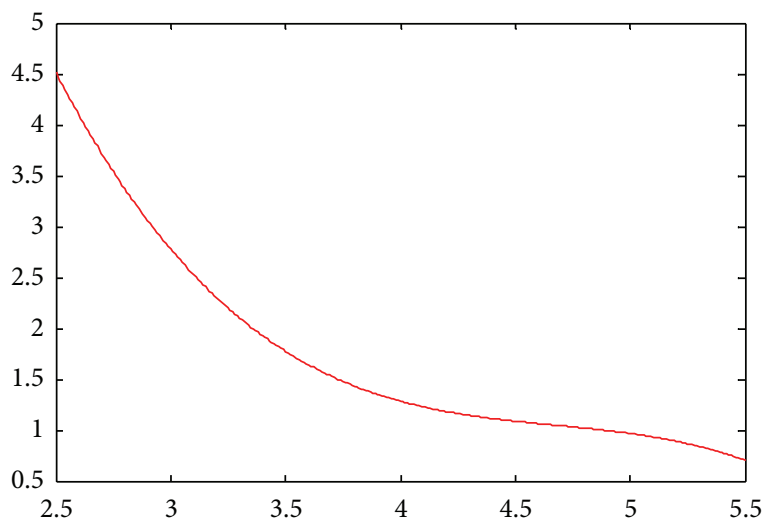

FIGURE 7: The diagram of Malmquist product index $\mathrm{DMU}_{7}$.

$$
\begin{aligned}
& S_{2} \\
& =\int_{2.6675}^{3.6872}\left(-2.1667 t^{3}+26.333 t^{2}-101.153 t+124.5783\right) d t \\
& =0.2037 .
\end{aligned}
$$

By this application, all units have progress in the study time interval. It is obvious that, by interval increasing and studying the bank branches for a year, the results may be changed. Some units have progress in supposed interval but show regress in some subintervals, and vice versa. These results and study helped the bank managers to render the units at short and long terms.

\section{Conclusion}

The proposed and study method reported here is a valuable scientific method. This method is applicable for examining and analyzing time dependent inputs and outputs. This introduced function is a calculating function and solves less linear programing. This simple function could be used to evaluate the progress and regress of each or several units with the time. It is very suitable for application programing. It 


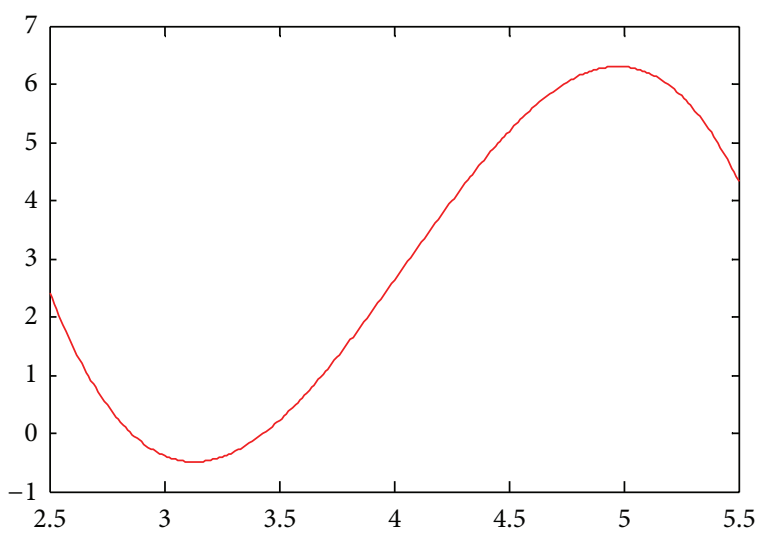

FIGURE 8: The diagram of Malmquist product index $\mathrm{DMU}_{8}$.

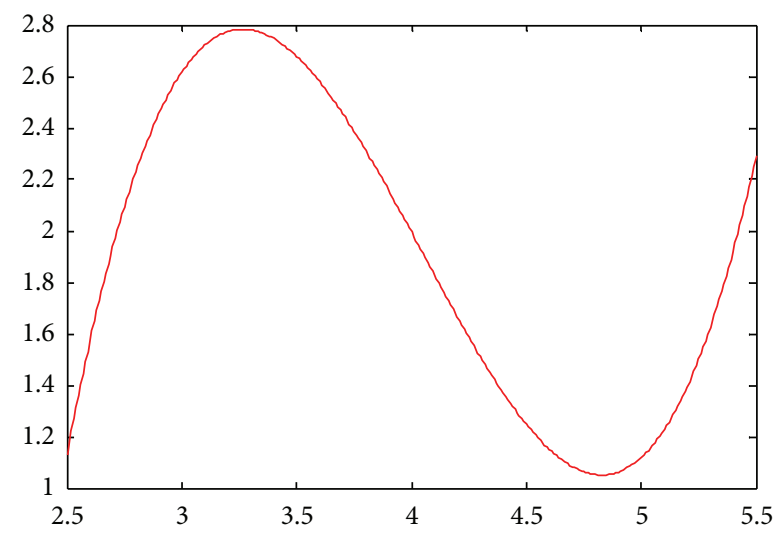

FIgURE 9: The diagram of Malmquist product index $\mathrm{DMU}_{9}$.

foresees the other data out of the supposed interval and offers the initial evaluation.

\section{Conflict of Interests}

The authors declare that there is no conflict of interests regarding the publication of this paper.

\section{References}

[1] F. H. Lotfi, G. Jahanshahloo, M. Vaez-Ghasemi, and Z. Moghaddas, "Periodic efficiency measurement for achieving correct efficiency among several terms of evaluation," International Journal of Operational Research, vol. 18, no. 1, pp. 1-15, 2013.

[2] F. Hosseinzadeh Lotfi, G. R. Jahanshahloo, M. Khodabakhshi, M. Rostamy-Malkhlifeh, Z. Moghaddas, and M. Vaez-Ghasemi, "A review of ranking models in data envelopment analysis," Journal of Applied Mathematics, vol. 2013, Article ID 492421, 20 pages, 2013.

[3] A. Charnes, W. W. Cooper, and E. Rhodes, "Measuring the efficiency of decision making units," European Journal of Operational Research, vol. 2, no. 6, pp. 429-444, 1978.

[4] M. Khodabakhshi, "Estimating most productive scales size with stochastic data in data envelopment analysis," Economic Modelling, vol. 26, no. 5, pp. 968-997, 2009.
[5] G. R. Jahanshahloo and M. Khodabakhshi, "Using input-output orientation model for determining most productive scale size in DEA," Applied Mathematics and Computation, vol. 146, no. 2-3, pp. 849-855, 2003.

[6] S. Malmquist, "Index numbers and indifference surfaces," Trabajos de Estadistica, vol. 4, pp. 209-242, 1953.

[7] R. Eslami, M. Khodabakhshi, G. R. Jahanshahloo, F. H. Lotfi, and M. Khoveyni, "Estimating most productive scale size with imprecise-chance constrained inputoutput orientation model in data envelopment analysis," Computers and Industrial Engineering, vol. 63, no. 1, pp. 254-261, 2012.

[8] R. Fare, S. Grosskopf, M. Norris, and Z. Zhang, "Productivity growth, technical progress, and efficiency change in industrialized countries," American Economic Review, vol. 84, no. 1, pp. 66-83, 1994.

[9] Y. Chen and A. I. Ali, "DEA Malmquist productivity measure: new insights with an application to computer industry," European Journal of Operational Research, vol. 159, no. 1, pp. 239-249, 2004.

[10] R. M. Thrall, "Measures in DEA with an application to the Malmquist index," Journal of Productivity Analysis, vol. 13, no. 2, pp. 125-137, 2000.

[11] R. Althin, "Measurement of productivity changes: two Malmquist index approaches," Journal of Productinity Analysis, vol. 160, pp. 107-128, 2001.

[12] F. H. Lotfi, G. Jahanshahloo, M. Vaez-Ghasemi, and Z. Moghaddas, "Modified Malmquist productivity index based on present time value of money," Journal of Applied Mathematics, vol. 2013, Article ID 607190, 8 pages, 2013.

[13] S. A. Berg, F. R. Forsund, and E. S. Jansen, "Malmquist indices of productivity growth during the deregulation of Norwegian banking," Scandinavian Journal of Economics, vol. 94, supplement, pp. S211-S228, 1992.

[14] A. B. Bernard and C. I. Jones, "Comparing apples to oranges: productivity convergence and measurement across industries and countries," The American Economic Review, vol. 86, no. 5, pp. 1216-1238, 1996.

[15] N. Maniadakis and E. Thanassoulis, "A cost Malmquist productivity index," European Journal of Operational Research, vol. 154, no. 2, pp. 396-409, 2004.

[16] H. Jahanshahloo, F. Hosseinzadeh Lotfi, and M. Khodabakhshi, "Modified nonradial supper efficiency models," Journal of Applied Mathematics, vol. 2014, Article ID 919547, 5 pages, 2014.

[17] M. Khodabakhshi, M. Asgharian, and G. N. Gregoriou, "An input-oriented super-efficiency measure in stochastic data envelopment analysis: evaluating chief executive officers of US public banks and thrifts," Expert Systems with Applications, vol. 37, no. 3, pp. 2092-2097, 2010.

[18] A. Charnes, W. W. Cooper, Z. M. Huang, and Q. L. Wei, "Cone ratio data envelopment analysis and multi-objective programming," International Journal of Systems Science, vol. 20, no. 7, pp. 1099-1118, 1989.

[19] W. W. Cooper, K. S. Park, and J. T. Pastor, "RAM: a range adjusted measure of inefficiency for use with additive models, and relations to other models and measures in DEA," Journal of Productivity Analysis, vol. 11, no. 1, pp. 5-42, 1999.

[20] M. J. Farrell, "The measurement of productive efficiency," Journal of the Royal Statistical Society A, vol. 120, no. 3, pp. 253281, 1957. 


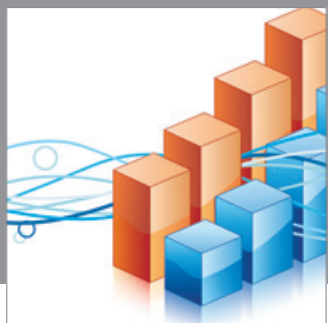

Advances in

Operations Research

mansans

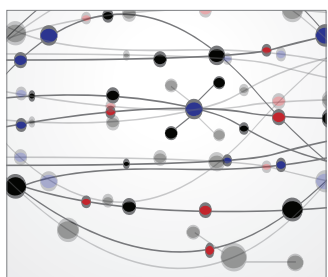

The Scientific World Journal
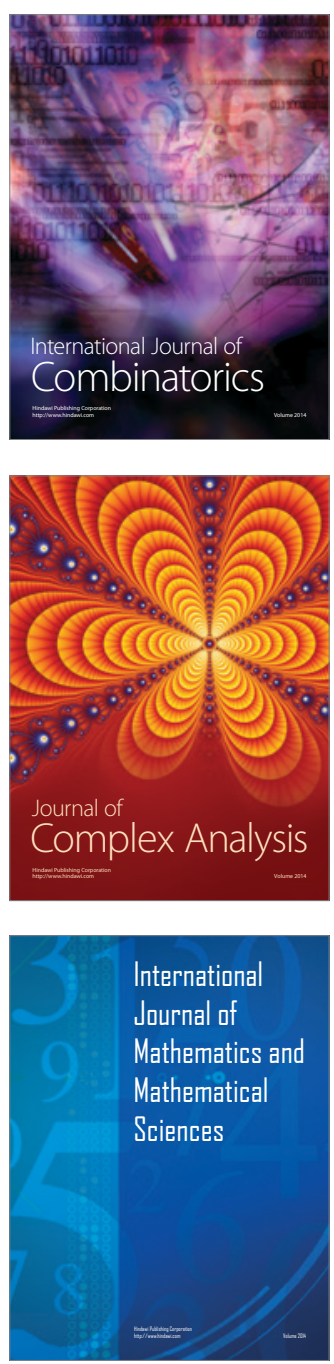
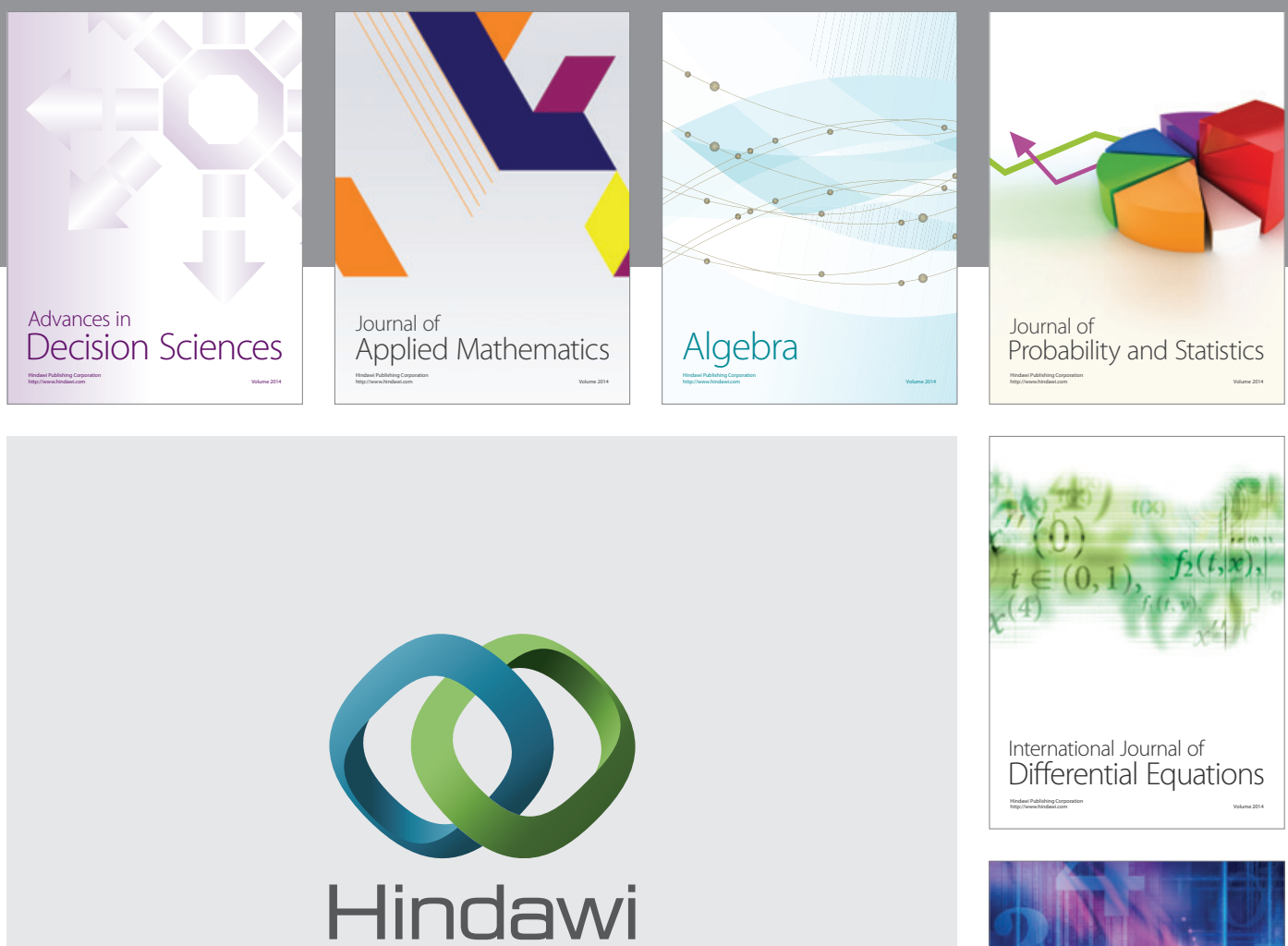

Submit your manuscripts at http://www.hindawi.com
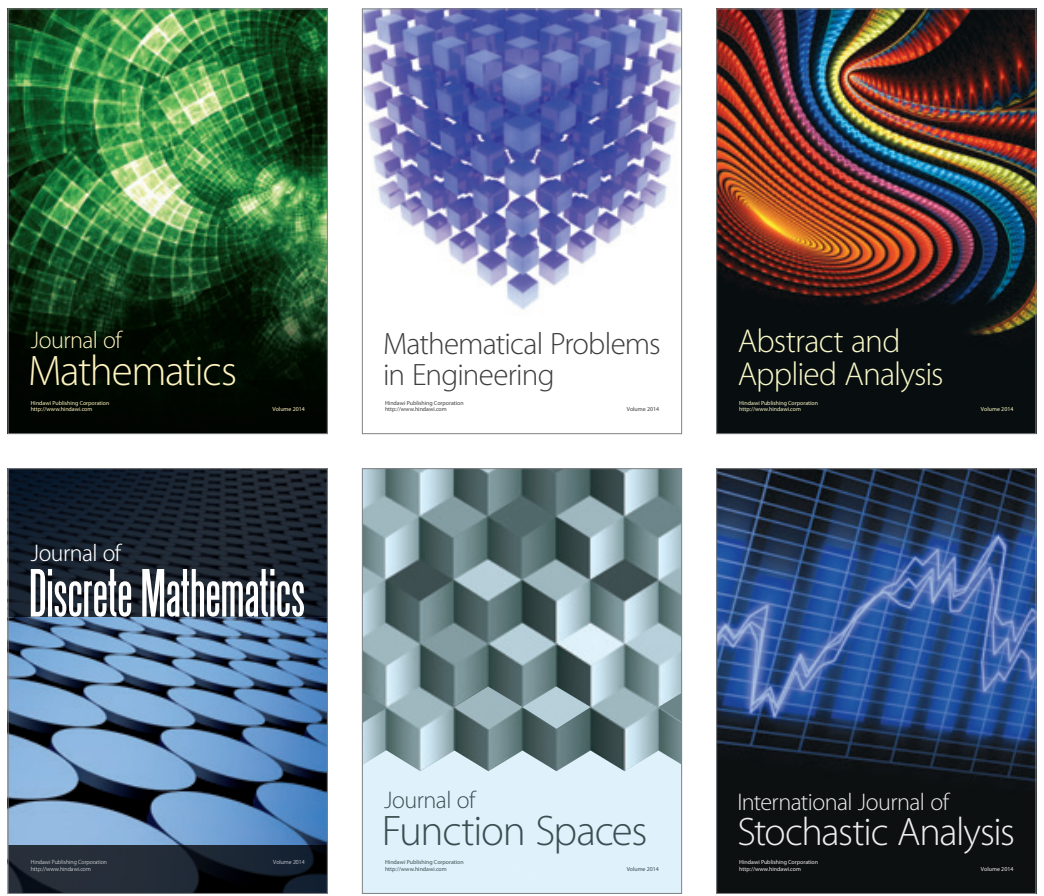

Journal of

Function Spaces

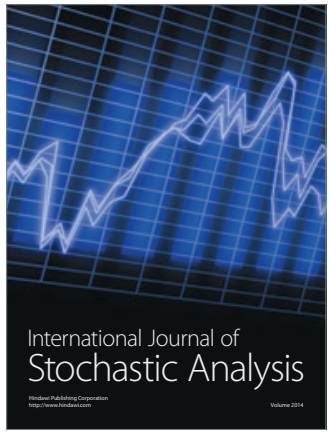

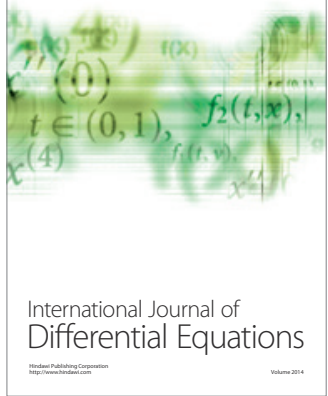
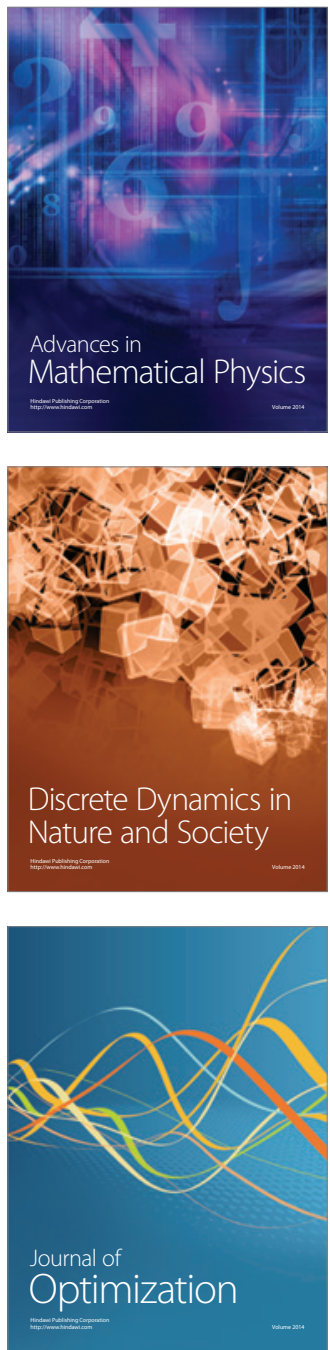